\title{
Flutuação populacional de conídios de Cercospora beticola no ar e sua relação com a severidade da cercosporiose da beterraba
}

\author{
Leandro Luiz Marcuzzo $^{1} \oplus$, Aline Nascimento ${ }^{1,2} \oplus$, Sheila Chaiana Harbs ${ }^{1,3} \oplus$
}

${ }^{1}$ Instituto Federal Catarinense - IFC/Campus Rio do Sul, CP 441, CEP 89.163-356, Rio do Sul-SC, Brasil. ${ }^{2}$ Aluna do curso de agronomia e bolsista de iniciação científica PIBIC/CNPq. ${ }^{3}$ Aluna do curso de agronomia e bolsista de iniciação científica IFC/Campus Rio do Sul.

Autor para correspondência: Leandro Luiz Marcuzzo (leandro.marcuzzo@ifc.edu.br)

Data de chegada: 20/12/2017. Aceito para publicação em: 07/04/2020.

$10.1590 / 0100-5405 / 189359$

\section{RESUMO}

Marcuzzo, L.L.; Nascimento, A.; Harbs, S.C. Flutuação populacional de conídios de Cercospora beticola no ar e sua relação com severidade da cercosporiose da beterraba. Summa Phytopathologica, v.46, n.2, p.164-166, 2020.

Em experimento de campo nos anos de 2016 e 2017 quantificou-se a flutuação de conídios de Cercospora beticola e sua relação com a severidade da cercosporiose da beterraba. Sementes de beterraba da cultivar Boro foram semeadas em quatro repetições onde foram avaliadas 80 plantas. Os conídios foram coletados através de um coletor de esporos tipo "cata-vento", contendo uma lâmina de microscópio untada com vaselina, a qual era quantificada semanalmente com auxílio de microscópio. A severidade da doença foi analisada através de escala diagramática para avaliação da porcentagem de área foliar afetada pela doença. O número de conídios e a severidade da cercosporiose da beterraba foram submetidos ao cálculo do coeficiente de correlação linear de Pearson (r). Nos anos de 2016 e 2017 a coleta de conídios ocorreu concomitante à constatação da doença, provavelmente devido haver inóculo no ar. A correlação entre as variáveis flutuações de conídios e a severidade da doença foi significativa, com r=0,762 e r=0,768 para os anos de 2016 e 2017 respectivamente. A severidade da doença em beterraba é influenciada pela presença dos conídios coletados do ar.

Palavras-chave: Beta vulgaris ssp. vulgaris, aerobiologia, epidemiologia.

\section{ABSTRACT}

Marcuzzo, L.L.; Nascimento, A.; Harbs, S.C. Populational fluctuation of Cercospora beticola conidia in the air and its relationship with the severity of Cercospora leaf spot of beets. Summa Phytopathologica, v.46, n.2, p.164-166, 2020.

In a field trial in 2016 and 2017, the fluctuation of Cercospora beticola conidia was quantified, as well as its relationship with the severity of Cercospora leaf spot in beets. Beet seeds of cultivar Boro were sown in four replicates, resulting in the evaluation of 80 plants. Conidia were collected by a "vane"-type spore trap containing a microscopic slide smeared with petroleum jelly, which was weekly quantified under a microscope. The disease severity was analyzed through a diagrammatic scale to evaluate the percentage of leaf area affected by the disease. The number of conidia and the severity of Cercospora leaf spot of beets were subjected to the calculation of Pearson correlation coefficient (r). In 2016 and 2017, the collection of conidia occurred concomitantly with the manifestation of the disease, probably because there was inoculum concentration in the air. The correlation between the variables fluctuation of conidial population and disease severity was significant, showing $\mathrm{r}=0.762$ and $\mathrm{r}=0.768$ for 2016 and 2017 , respectively. The severity of the disease in beets is influenced by the presence of conidia collected from the air.

Keywords: Beta vulgaris ssp. vulgaris, aerobiology, epidemiology.

Dentre as doenças que atacam a cultura da beterraba e reduzem o seu potencial produtivo, a principal é a cercosporiose causada por Cercospora beticola Sacc. (3). Atualmente não há cultivares resistentes para essa doença, e, por isso, o seu controle vem sendo feito com pulverizações frequentes de fungicidas protetores e sistêmicos (10). Uma das maneiras de reduzir o uso de agrotóxicos é conhecer quais as condições que favorecem a ocorrência da doença, que envolvem o ambiente, o patógeno e o hospedeiro (1). Em relação ao patógeno, o detalhamento da dispersão anemófila de conídios da $C$. beticola no ar em área de cultivo constitui-se em uma informação importante no avanço do manejo fitossanitário $(2,8)$. Diante do exposto, este trabalho teve por objetivo avaliar a flutuação de conídios de C. beticola no ar em área de cultivo de beterraba e sua relação com severidade da cercosporiose da beterraba nos anos de 2016 e 2017.

O experimento foi realizado de 15 de setembro a 15 de dezembro nos anos de 2016 e 2017 no Instituto Federal Catarinense, Campus de
Rio do Sul, município de Rio do Sul/SC, com latitude Sul de 27¹1'07', longitude Oeste de 49³9'39” e altitude de 687 metros do nível do mar.

Os dados meteorológicos foram obtidos de uma estação Davis ${ }^{\circledR}$ Vantage Vue $300 \mathrm{~m}$ localizado ao lado do experimento e os dados médios durante a condução do experimento foram de 18,4 e $19,4^{\circ} \mathrm{C}$ para temperatura do ar, de 12,8 e 12,8 horas de umidade relativa do ar $\geq 90 \%$ e a precipitação pluvial acumulada foi de 483,5 e $488 \mathrm{~mm}$ respectivamente para 2016 e 2017.

Sementes de beterraba da cultivar Boro foram semeadas a campo em quatro repetições constituídas de uma área de $5 \times 1,25 \mathrm{~m}$ cada e espaçamento de $25 \times 12,5 \mathrm{~cm}$ entre plantas. Cada repetição continha 5 fileiras com 150 plantas cada e 20 plantas dessas foram previamente demarcadas de forma aleatória nas três filas centrais para a avaliação da severidade da doença. A calagem, adubação e tratos culturais seguiram as normas recomendadas para a cultura $(3,10)$, porém não foi utilizado fungicida. 
Para que houvesse inóculo na área, mudas de beterraba cv. Boro com 30 dias de idade foram inoculadas com auxílio de um atomizador portátil uma suspensão $\left(10^{4}\right)$ de conídios de C. beticola e após 24 horas de camara úmida foram transplantadas a cada um metro linear ao redor do experimento no dia da semeadura.

A coleta dos conídios de $C$. beticola no ar foi realizada através de um coletor de esporos tipo "cata-vento" (9), posicionado a 0,4 metros de altura, localizado no centro do experimento. No interior do coletor havia uma lâmina de microscópio $(7,5 \times 2,5 \mathrm{~cm})$ untada com vaselina a qual era substituída semanalmente. Em laboratório, a lâmina foi dividida em dois pontos centrais e adicionou-se 2 gotas de azul de metileno 33\% diluído em água foram depositadas lamínulas (1,8 x 1,8 $\mathrm{cm}$ ) correspondendo a uma área de $6,48 \mathrm{~cm}^{2}$. Através da visualização em microscópio ótico com a objetiva de 10 vezes, quantificou-se o número de conídios coletados semanalmente. A severidade da doença foi analisada através da porcentagem de área foliar afetada pela doença em cada folha exposta através da escala que varia de 0,41 a $23,61 \%$ proposta por May de Mio et al. (7). Para verificar a relação entre a flutuação de conídios e a severidade da cercosporiose da beterraba durante o ciclo da cultura, os dados foram submetidos ao cálculo do coeficiente de correlação linear de Pearson (r) e sua significância foi verificada valores críticos de correlação do teste.

Em ambos os anos de avaliação, a correlação de Pearson (r) entre o número de conídios coletados do ar e a severidade da doença foi significativa pelo teste à 1 e $5 \%$ (Tabela 1). Khan et al. (6) também verificam que a coleta de conídios esta associada $(\mathrm{P}<0,01)$ a doença na beterraba açucareira nos estados de Minnesota e Dakota do Norte nos Estados Unidos da América.

A coleta de conídios nos anos de 2016 e 2017 ocorreu concomitante à constatação da doença a campo na $4^{\mathrm{a}}$ semana após a semeadura (Tabela
1). Isso se deve ao inóculo já presente na área, pois Juliatti et al. (4) coletaram esporos da ferrugem asiática da soja somente após ocorrer a esporulação em plantas doentes.

Houve pouca oscilação no número de conídios coletados na mesma semana de avaliação entre 2016 e 2017 (Tabela 1), no entanto a severidade da doença em 2016 foi mais acentuada a partir da $7^{\mathrm{a}}$ semana e finalizando com $20,17 \%$, enquanto que em 2017 atingiu praticamente a metade, com $10,9 \%$ na $13^{\mathrm{a}}$ semana (Tabela 1 ). Isso se deve a estiagem durante o período de condução da cultura, que apesar da pouca diferença (5,5 $\mathrm{mm})$ na precipitação pluvial, as chuvas foram mais distribuídas em 2016, favorecendo o progresso da doença.

Após a quarta semana do aparecimento da doença no ano de 2016, observou-se um acréscimo gradual de severidade, que apesar do número de conídios coletados variou durante o período, ocorrendo seu pico na $11^{\mathrm{a}}$ semana e reduzindo-se nas duas semanas antes da colheita. Isso pode ser associado ao inóculo de que a planta já se encontrava em processo de senescência e também a grande taxa de infecção da cercosporiose, o que resultou na diminuição do número de esporos. A correlação entre os dados da severidade da doença e do número de conídios coletados foi significativa, $r=0,762$, (Tabela 1 ) indicando forte linearidade entre estas duas variáveis.

No ano de 2017, apesar de pouco variável o número de conídios entre a $4^{\mathrm{a}}$ e $7^{\mathrm{a}}$ após a semeadura, verificou-se que a severidade da doença progrediu lentamente durante esse período. O número de conídios mais que dobrou a partir da $7^{\mathrm{a}}$ semana, com exceção na penúltima semana, porém a doença foi gradativa durante esse período. A correlação $(\mathrm{r}=0,768)$ entre a flutuação de conídios e a severidade da doença foi forte e significativa no ano de 2017 (Tabela 1).

Keske (5) avaliando a flutuação de Monilia fructicola, agente causal da podridão parda do pessegueiro coletados em armadilhas

Tabela 1. Coeficiente de correlação (r) entre o número de conídios de Cercospora beticola coletados semanalmente e as respectivas severidades da cercosporiose em 2016 e 2017. IFC, Campus de Rio do Sul, SC

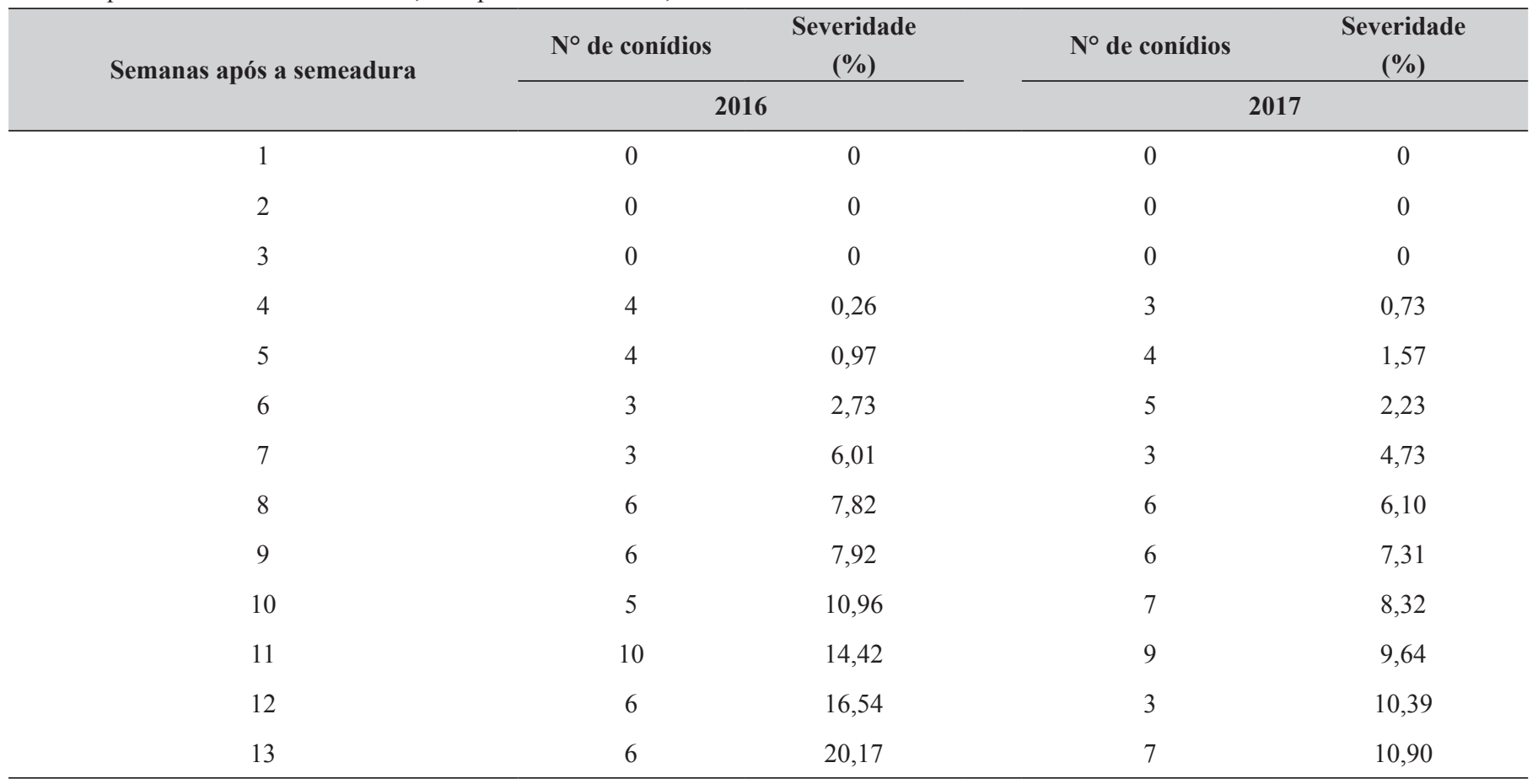

Coeficiente de correlação (r)

$0,762 *$

$0,768 *$

*significativo a 1 e $5 \%$ de pelo valor crítico do teste de correlação de Pearson. 
do tipo "cata-vento", observou que foi constante a coleta durante o período vegetativo da cultura, similar ao que ocorreu nesse trabalho. Outro aspecto verificado nesse trabalho em que a maior concentração de esporos ocorreu entre a $8^{\mathrm{a}}$ e $11^{\mathrm{a}}$ semana, fase de desenvolvimento vegetativo e formação do tubérculo o que também foi verificado na beterraba açucareira (6). Isso evidência que o inóculo presente no ambiente serve de um indicativo para a ocorrência da doença (8).

A presença de conídios de $C$. beticola é um indicador do aumento da severidade da cercosporiose da beterraba e pode ser usado futuramente como um indicador de controle em um sistema de previsão da doença.

\section{AGRADECIMENTOS}

Os autores agradecem a bolsa de iniciação científica PIBIC/Cnpq e IFC/Campus Rio do Sul para realização desse trabalho.

\section{REFERÊNCIAS}

1. Bergamim Filho, A; Amorim, L.. Epidemiologia de doenças de plantas. In: Amorim, L.; Rezende, J.A.M.; Bergamim Filho, A.; (Ed.). Manual de fitopatologia: princípios e conceitos. 4. ed. São Paulo: Ceres, 2011. v.1, cap.5, p.101-118.

2. Casa, R.T.; Reis, E.M.; Zambolim, L. Dispersão vertical e horizontal de conídios de Stenocarpella macrospora e Stenocarpella maydis. Fitopatologia Brasileira, Brasília, DF, v.29, n.2, p.141-147, 2004.
3. Ferreira, M.D.; Tivelli, S.W. Cultura da beterraba: recomendações gerais. Guaxupé, Cooxupé, 1989, 14p. (Boletim Técnico, 2).

4. Juliatti, F.C.; Rezende, A.A.; Vale, F.X.R. Critérios práticos de fundamento epidemiológico que auxiliam na tomada de decisão para o controle de doenças de plantas. Tropical Plant Pathology, Brasília, DF, v.35, p.23-25, 2010. Suplemento.

5. Keske, C. Epidemiologia da podridão parda em pessegueiros conduzidos em sistema de produção orgânico no alto vale do Itajaí - SC. 2009. 119f. Tese (Doutorado em Produção Vegetal) - Universidade Federal do Paraná, Curitiba.

6. Khan, J.; QI, A.; Khan, M.F.R. Fluctuations in number of Cercospora beticola conidia in relationship to environment and disease severity in sugar beet. Phytopathology, St. Paul, n.7, v.99, p.796-801, 2009.

7. May de Mio, L.L.; Oliveira, R.A.; Floriani, A.M.V.; Schuber, J.M.; Poltronieri, A.S.; Araujo, M.A.; Tratch, R. Proposta de escala diagramática para quantificação da cercosporiose da beterraba. Scientia Agraria, Curitiba, v.9, n.3, p.331-337, 2008.

8. Reis, E.M.; Mário, J.L. Quantificação do inóculo de Diplodia macrospora e de $D$. maydis em restos culturais, no ar, e sua relação com a infecção em grãos de milho. Fitopatologia Brasileira, Brasília, DF, v.28, n.2, p.143147,2003

9. Reis, E.M.; Santos, H.P. População de Helmintosporium sativum no ar quantificado através de uma armadilha tipo cata-vento. Fitopatologia Brasileira, Brasília, DF, v.10, n.5, p.515-519. 1985.

10. Tivelli, S.W; Factor, T.L.; Teramoto, J.R.S.; Fahi, E.G.; Moraes, A.R.A.; Trani, P.E.; May, A. Beterraba, do plantio à comercialização. Série Tecnologia APTA. Boletim Técnico IAC, 210. Campinas: Instituto Agronômico. 2011, 45p. 